\title{
Extrinsic factors influencing gut microbes, the immediate consequences and restoring eubiosis
}

\author{
Ousman Bajinka ${ }^{1,2,3}$, Yurong Tan 1,2,3*, Khalid A. Abdelhalim , Güven Özdemir ${ }^{4}$ and Xiangjie Qiu ${ }^{1}$
}

\begin{abstract}
From the emerging studies, the more diverse the microbial population in the gut, the healthier the gut. Health benefits are associated with the functional characteristics of these diverse microbial genes. Extrinsic factors causing dysbiosis are extensively studied however, linking the varying degree of consequences to the respective factors and therapeutic possibilities are not explored at length. This review aims to examine from previous studies and put forward the types of dysbiosis, the immediate consequences and the scientific approaches to restore disrupted microbiota. Dietary supplements are found to be one of the factors contributing profoundly to the alteration of gut microbiota. While diet rich in fibre and fermented food established a diverse microbiome and produce vital metabolites, high fat, animal proteins and high caloric carbohydrate are as well relative to dysbiosis among infants, adult or diseases individuals. The intermittent fasting, feeding methods, the $\mathrm{pH}$ and water quality are among the factors associated with dysbiosis. Prebiotics and Probiotics maintain and restore gut homeostasis. Antibiotic-induced dysbiosis are relatively on the spectrum of activity, the pharmacokinetics properties, the dose taken during the treatment route of administration and the duration of drug therapy. The higher the altitude, the lesser the diversity. Extreme temperatures as well are related to reduced microbial activity and metabolism. Delivery through caserium-section deprived the newborn from restoring valuable vaginal bacterial species and the baby will instead assumed intestinal microbiota-like. While exercise and oxidative stress contribute even though moderately, fecal microbial transfer (FMT) also influence gut microbiota.
\end{abstract}

Keywords: Gut microbiota, Dysbiosis, Mediterranean diet, Inflammatory bowel diseases

\section{Introduction}

One of the recent human health and diseases are the factors associated with dysbiosis. Dysbiosis is the reduced diversity of gut microbiota and restoring the lost microbiota to a much diverse composition is eubiosis. Are dysbiosis a result or causation is still in the mystery, partly due to circumstantial or speculative nature of the gut mechanisms. These factors influencing gut microbiota are in a constant flow and the gut with repertoire of microbes is resilient enough to adjust to any variation. In addition

\footnotetext{
${ }^{*}$ Correspondence: yurongtan@csu.edu.cn

${ }^{2}$ Department of Medical Microbiology, Central South University,

Changsha 410078, Hunan, China

Full list of author information is available at the end of the article
}

to natural variations, the immune system, the intestinal mucosa, microbiota itself, diet and ingested drugs are major factors influencing dysbiosis. What lies illusive until today are the mechanisms underpinning dysbiosis. These mechanisms are not thoroughly explored due to our limited characterizing techniques. The intricate interactions among species such as, the role of parasites, virus, bacteriophages and fungi in addition to natural variations such as, stress, secretions of bacterial toxins etc. when explored, will add weight to the current existing knowledge. Until the science regarding the above pathological effects is bridged to the effects they do cause to dysbiosis, the role of microbiota in health and disease would not be better understood (Travisano and Velicer 2004; Sartor and Mazmanian 2012; Ma et al. 2019).

\section{Springer Open}

(c) The Author(s) 2020. This article is licensed under a Creative Commons Attribution 4.0 International License, which permits use, sharing, adaptation, distribution and reproduction in any medium or format, as long as you give appropriate credit to the original author(s) and the source, provide a link to the Creative Commons licence, and indicate if changes were made. The images or other third party material in this article are included in the article's Creative Commons licence, unless indicated otherwise in a credit line to the material. If material is not included in the article's Creative Commons licence and your intended use is not permitted by statutory regulation or exceeds the permitted use, you will need to obtain permission directly from the copyright holder. To view a copy of this licence, visit http://creativeco mmons.org/licenses/by/4.0/. 
Furthermore, some elements surface; due to the available biochemical niches in the gut, microbes developed resiliency towards the lifestyles of the host. For example, the time and type of food consume by the host are naturally checked. Each for dietary type is specific to group of distinct phyla or class of bacteria. The more abundant they are with respect to phyla, the more adaptable they are to any biochemical changes (Sartor and Mazmanian 2012).

Human metabolism is indeed well explored, energy is generally derived via fermentation and sulphate reduction of dietary and host carbohydrates. Our gut is a complex organ harboring trillions of microorganisms that reside both as commensal and pathogens. In a balance healthy gut, the pathogenic group are dominated by the commensals. These commensals balance the gut microbiota and hence no infection or significant shift towards pathogenic bacterial overgrowth is observed (Thaiss et al. 2016). Depending on the biochemical and physiological properties in human body, microbes are dispersedly distributed. They can be found in the mouth, on the skin, genital tract and in the gut. Acidophilic species such as Streptococcus, Lactobacillus, Helicobacter Pylori, Candida and Peptostreptococcus are found in the stomach, Lactobacillus and Streptococcus are found in duodenum, jejunum and proximal ileum (Travisano and Velicer 2004). The further you go from esophagus to the rectum, the less acidic it become and the number of bacteria are on ascending trend towards the colon. More than 100 species from Actinomycinae, Bacteroidetes, Streptococcus, Clostridium and Corynebacteria spp. are concentrated in the distal ileum. More than 1000 species mainly, Bacteroidetes, Clostridium Type IV and XIV and Enterobacteriaceae are found in the colon (Sartor and Mazmanian 2012; Thaiss et al. 2016). With the limited molecular and genomics techniques, the study of gut microbiome in health and disease is not species specific instead clusters of bacteria forming genera. Studies have found that Firmicutes and Bacteroidetes with $64 \%$ and $23 \%$ respectively are the most common in individuals. Nevertheless, Actinobacteria and Proteobacteria are also present in varying percentages (Sartor and Mazmanian 2012). Until today, there is no such as to what is a normal gut microbiota. However, abundance in Proteobacteria in the gut is studied to be associated with inflammation at the mucosal wall and this, in effect leads to disruption of epithelial lining. Excess Firmicutes and metabolic disorders are associated with obesity (Kasai et al. 2015; Ley et al. 2008).

The knowledge gap in gut microbiota medicinal approach is not bridged completely. Microbes residing in the intestinal tract influence local and systemic process of the host such as supplying vitamin, maturation of mucosal immunity, nutrient transformation, influence on the brain and neurotransmitter (Peng et al. 2018).
Balance microbiota is studied to be a more diverse population, which is profoundly associated with a healthy gut. Based on the recent Metagenomics analysis, a healthy human gut comprises mainly Bacteroidetes, Firmicutes, Actinobacteria and Proteobacteria (Arumugam et al. 2011). Any shift in these communities of gut bacteria results in an imbalance or dysbiosis in the gut microbiota. Dysbiotic or less diversed microbial community in the gut is studied to be associated with the onset of diseases or the driving force behind diseases mechanism such as metabolites (Kasai et al. 2015). The longevity of a host is determined by the ability of specific microbes contributing to the range of essential functions that ascertain the normal healthy function or restoring a balance diversity (eubiosis) in the gut. An essential function in the gut herein refers to the digestive role, absorption of nutrients and excretion of waste (Travisano and Velicer 2004). Gut microbiota stimulates the immune system and plays a key role in cell regeneration, produce enzymes, vitamin $\mathrm{K}$ and biotin. They enable the digestion of polysaccharides and influence bacteria in the gastrointestinal tract (GI) tract and influence host's metabolism. Polysaccharides, as prebiotics components, are being speculated to confer positive effects in managing metabolic diseases like obesity and diabetes (Lupp et al. 2007).

Apart from heredity factors that are even known to have lesser influence on the gut, drugs such as antibiotics, non-steroid drugs, chemotherapy, radiotherapy and poor nutrition are the extrinsic factors. Diseases, physical and psychological stress, are the intrinsic factors studied to cause dysbiosis. The resulting consequences of all these factors are dysregulation of immune system, leading to autoimmune diseases, onset of disease such as inflammatory bowel diseases (IBD), colorectal cancer and metabolic disorders such as diabetes. Number of studies have established facts on the complex microbial community in the gastrointestinal tract as essential for human health (Ley et al. 2008; Frank et al. 2007). While there are other factors inflicting alteration in the gut microbiome, causing dysbiosis and leading to number of complications, this review is set to examine the extrinsic factors influencing gut microbes, the immediate consequences caused and the mechanisms studied to reinstate the gut to a healthy function. Since it is a newly born discipline, we draw much attention on the number of publications centered on dysbiosis and extended the scope dating back to 20 years (Fig. 1) (Additional file 1: Figure 1).

\section{The effects of dietary on gut microbiota}

Apparently, we are what we eat, so we should eat the right food. Food can be served as medicine, preventing and treating diseases and in fact food was used as antimicrobial in the era of pre-antibiotics. Our dietary patterns 


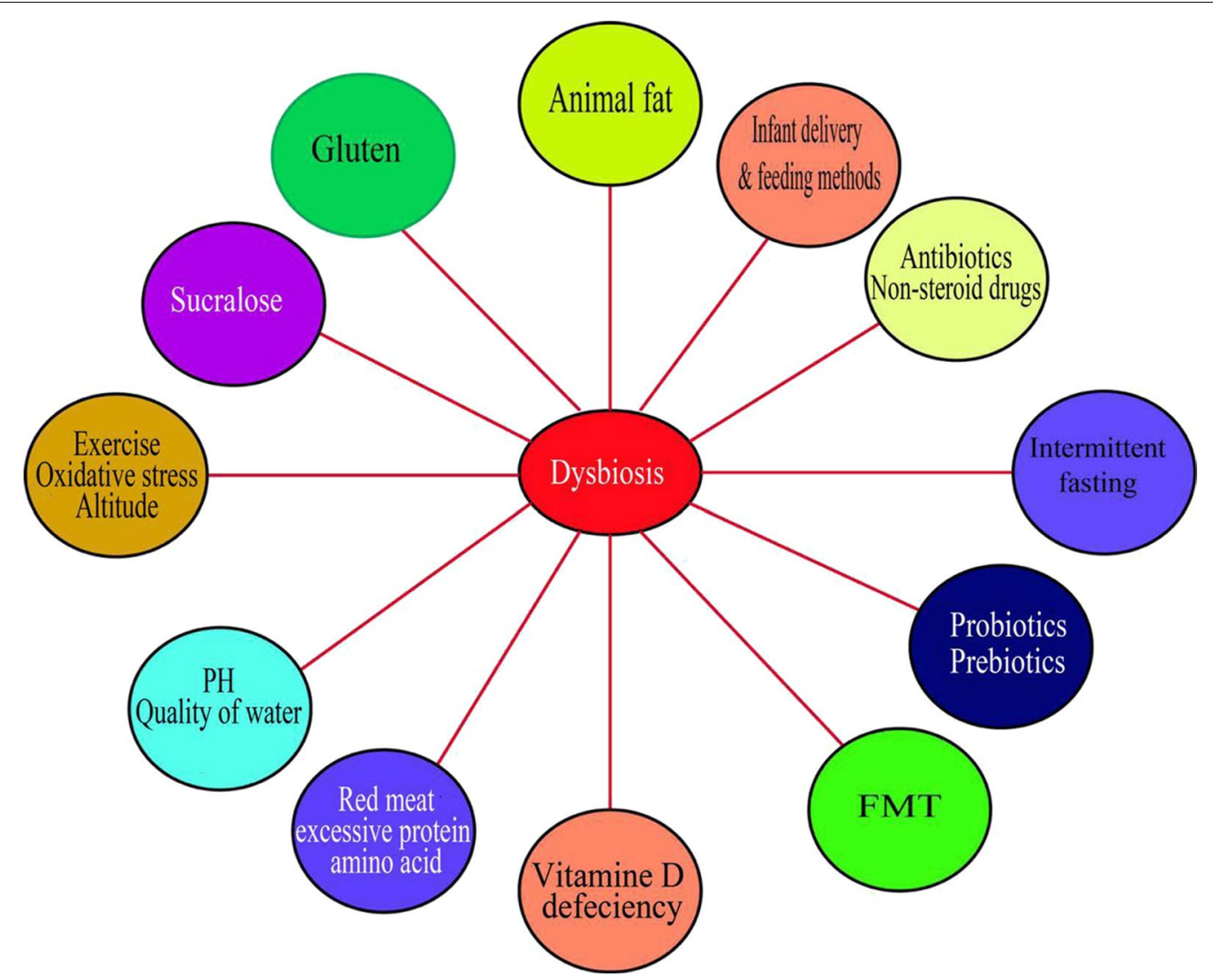

Fig. 1 Factors causing alteration to gut microbiota. Diet rich in protein, animal fats and high carbohydrate, sucralose and diet containing gluten all contributed to dysbiosis. Exercise and intermittent fasting are studied to both starve the bad microbes and clean the gut. Method of delivery for the newborn baby and the feeding methods determine the childhood immunity and this period is crucial for the development of human life. The $\mathrm{pH}$ level or water quality are as well among the factors associated with dysbiosis. In addition, drugs including antibiotics, non-steroids anti-inflammatory drugs, Prebiotics and Probiotics adversely affected the gut microbiota composition. Other factors are vitamin D deficiency, oxidative stress, temperature and fecal microbial transfer

have direct influence on the occurrence and variety of bacteria in the gut, which consequently affects our health. Fascinating findings on food science do not only confer high nutritive benefits to humans, but is also the medicinal use attached to food industries. It is believed to be a major breakthrough in medicine; simply changing diet can save us from the cost of treatment. Modern diets or western diets caused lots of preventable diseases like asthma, obesity, multiple sclerosis, etc.

The effects and influences of diets on our gut microbiome is not a new area of study. The meta-transcriptomic studies have revealed profound evidence and set aside multiple conditions. The ideal microbiota is achieved through the capacity of the microbial members to metabolize sugars, and the 'reflective adaptation' of the microbiota to the available nutrient in the intestine (Zoetendal et al. 2012). Foods are to be explored and going far and wide means eating more and wild, thus the diversity of microbes, and a healthy gut microbiota. The transient changes brought to the gut microbiota composition by food are mainly due to fish, meat and fibers with durable effects. It was the classes of food that was put into the scope of nutrition studies. However, with gut microbiota medicine, the role of gut microbiota in diseases is attracting much attentions. One diet can contain more than two macronutrients and effects changes on gut microbiota while significantly influencing the metabolic output (Qiu et al. 2020).

\section{Dietary fibre}

Studies have correlating results on the beneficial effects of dietary fibreon human metabolism. Meta-analysis showed a clear link between dietary fibre and wide range of pathologies (Qiu et al. 2020). One of the recent interventions showed that dietary fibre could significantly reduce the insulin resistance among patients with type 2 diabetes. Moreover, clear links have been seen in dietary fibreshifting the microbiota and beneficial metabolites 
such as butyrate (Silva et al. 2020). While feeding on all the classes of foods is imperative to our health, diet rich in fibre stands prominent in maintaining the diversity of the gut microbiota (Zhang et al. 2013). For example, colonic microbiota is determined to a larger extent by the availability of microbiota-accessible carbohydrates (MACs) found in the dietary fibre we consume. Furthermore, the more extreme we go with strict 'animal-based' diets or 'plant-based' results into some extent of dysbiosis (David et al. 2013). Fibre has been the most studied food. Its influence on the small intestinal bacteria is understood to be enriching the gut with variety of benign microbial metabolism.

A crossover or a comparative study based on diets showed that, the influence of diets highly rich in resistance starch or non-starch polysaccharide fibre resulted in the enrichment of diverging pattern in bacterial growth (Gibson 2017). In fact, during the microbial digestion or breakdown of food residue or chyme, finest food particles or molecules cross the epithelial barrier to the blood stream or serum. If these molecules are highly concentrated with fibre, they serve as an antioxidants and hence cleansing mechanism in the blood stream. In contrast, uremic toxins are secreted into the gut with an increased protein fermentation as well as phenols, indoles, thiols and ammonia (Schultz et al. 2009). These are either anti-inflammatory or antioxidant in the gut. Microbial fermentation existing with the uptake of dietary fibre is by far the maximum utilization of energy in the gut. The indigestible diet rich in fibre reached the colon when the host cells could not secrete specific enzyme to act on it, thus they are fermented on by the gut microbes (Silva et al. 2020). The increase in abundance of Firmicutes over Bacteroidetes enable the gut to provide more enzymes for digesting any indigestible polysaccharide supplied from dietary fibre (Qiu et al. 2020). The more the microbes digest these polysaccharides, the more monosaccharides and hence an increased production of short chain fatty acid (SCFA) by the intestinal mucosa. Monocarbides are studied to augment lipid fat stores in peripheral tissue through the de novo hepatic lipogenesis with transcribed genes (Spanogiannopoulos et al. 2016). Monocarbides produce SCFAs that are specific for various energy supply such as colon cell proliferation and differentiation by Butyrate. Supply of energy lipogenesis in peripheral tissues is modulated by acetate and gluconeogenesis in the liver by propionate (Guarner and Malagelada 2003; Bäckhed et al. 2004).

\section{High fat diet}

High fat diet intake is found to be have detrimental effects on the penetrability of the mucus layer and also obstruct metabolic functions. These studies were conducted on a separate timeline and yet, correlating results where achieved. An increased in Firmicutes and decrease in relative abundance of Bacteroidetes is studied to be associated with high fat diet (Zhang et al. 2012). Akkermansia muciniphila, Actinobacteria and lactic acid bacteria with their protective functional genes influence the gut microbiota through diet rich in unsaturated fat. In contrast to unsaturated fat, saturated fat in mice model, lipopolysaccharide (LPS) production is prominent. Also the expressions of TLR4 and TLR2 have increased significantly (Yee et al. 2013). A very strong antimicrobial activity such as low $\mathrm{pH}$ is produced in the gut through the re-absorption of bile acids in the distal ileum. These bile acids are emulsified through the high intake of dietary lipids. High fatty acid diet is associated with ulcerative colitis (UC) and increase risk of colon cancer. The dietary administration of insulin is believed to prevent the advent of these detrimental effects (Frank et al. 2007). Furthermore, butyrate is playing a role in preventing oxygen induced gut microbiota dysbiosis and due to this, the consumption of dietary fibre is medically recommended for maintaining the normal mucosal barrier function in the gut (Zoetendal et al. 2012). In addition, Butyrate reduces bacterial translocation, improves the organization of tight junctions and stimulates the synthesis of mucin, a glycoprotein maintaining the integrity of the intestinal epithelium (Travisano and Velicer 2004).

\section{Animal fats and amino acids}

Diet based on animal fats and amino acids show an increased rate of Bacteroides and low protein while diet much depending on carbohydrate gives abundance in phylum Prevotella (Saha et al. 2017). Based on rat model, instead of Bacteroides, high-protein diet is associated with a decreased abundance of Clostridium species and Faecalibacterium prausnitzii (Liu et al. 2014). The production of branch chain fatty acids is prominent however, prominent as well is a potential toxic substance such as ammonia, sulfide and $N$-nitroso compounds, which are associated with high-protein diet (Wang et al. 2013). Excess in protein and amino acids synthesis more nitric oxide that influence the gut microbiota, leading to IBD, such as Crohn's disease (CD) (Magee et al. 2000).

\section{Sucralose}

An increased in the gut bacterial pro-inflammatory genes and unpredictable faecal metabolites was observed in mice given sucralose for 6 months (Zhang et al. 2012). Another interesting study reveals that sucralose, aspartame and saccharin can cause dysbiosis in gut microbiota. When compared to those fed with non-sucralose, rats were seen with significantly higher proportions of 
Clostridia, Bacteroides, and total aerobic bacteria in their gut and a rise in gut $\mathrm{pH}$ (Schultz et al. 2009).

\section{Mediterranean diet}

Mediterranean diet is one such diet enhancing a healthy gut. This diet is characterized by olive oil and oily fish (rich in mono and polyunsaturated fatty acids). Also is a high intake of fruit and vegetables (rich in fibre, antioxidants and vitamins), and whole grains and nuts (Sartor and Mazmanian 2012). To attain the most efficient nutrients from this type of diet, it has to be daily or weekly consumption based on the standardized food pyramid. One of the foods still in the debate between regulatory agencies and gut microbiologist is the high-intensity sweeteners used as sugar alternatives. These are believed to be minimal calories. They are regarded healthy to consume however, recent studies have shown that these substitutes may have some negative effects on the gut microbiota (Nettleton et al. 2016).

\section{Vegan's diet}

The debate on vegans eating healthy food better than non-vegans is still strong and to extent a sensitive topic. Considering the bad experiences with food, our apetite can be influenced and this affect the next food to choose. Advertisement, culture or people around can influence what meal we have on the table. Several studies including the one that recruited 15 vegans and 16 omnivores revealed amazing results. Despite, the differences in the serum metabolites between both groups, the gut bacterial community shows insignificant diversity (Wu et al. 2016). This must not be a good news for both the vegans and omnivores group. Furthermore, another randomized trial on 10 human omnivores were on either a high fat and low fibre diet or low fat and high fibre for a period of 10 days corroborated the results of this finding. Again, the microbiome composition has not been shaken and the differences in short chain fatty acid production was not significant. Perhaps the experiments should be extended for a longer period of time. This may assure bacterial derived metabolome to be influenced by being a vegan or not (Wu et al. 2016).

\section{Gluten}

Based on the studies of micro nutrients, gluten-free bread reduces the microbiota dysbiosis. Meaning they created a well-balanced microbial community as seen in vitro animal study (Bonder et al. 2016). People with gluten sensitivity or coeliac disease must have welcomed this news after this study was published. 21 healthy people with a profound diversity in the gut microbiota, just after 4 weeks on a gluten-free diet showed a balance diversity. However, among these, are good number who showed a lower abundance of the most common and important microbial species in the gut (Lebwohl et al. 2017). It may be too soon to conclude anything as scientists are still in the lab. In contrast to the coeliac disease related research above, until today, some people avoid gluten and yet they do not have the coeliac diseases or even proven gluten intolerance. In fact, from one of the observational studies, heart diseases were seen with an increasing rate among gluten avoiders (Schroeder et al. 2018). Moreover, it is speculated that perhaps the reduced consumption of whole grains is not good for maintaining the health of some organs. However, more knowledge is required to shed more light on these assumptions.

\section{Dietary gut therapy}

With the overfeeding hypothesis, homeostatic are disrupted due to over feeding, leading to dysbiosis, metabolic disorders and diseases (Lachnit et al. 2019; Kim et al. 2014). This is eminent in diet with low-fibre content, easily digestible and energy-dense, all influence the functional genes. Intermittent fasting is ascertained to confer changes in cellular pathways, preventing the development of diseases such as rheumatoid arthritis, obesity, hypertension and asthma, and delay in aging (Longo and Mattson 2014). Human has a set of factors that form mucosal environment and any uncontrolled growth of bacterial population through overfeeding with western-style diet (WSD) impairs carbon to nitrogen to phosphorous ration. Since these diets are easily digestible by both human cells and the microbes, diets rich in sugars, fats, and proteins with small amounts of fiber, lead to imbalance nutrient in the gut. This result to depilation of mucosal barrier and the onset of infections. However, the release of bacterial by-products stimulate the functionalities of immune cells through non-self-recognition of immune reactions thereby initiating immune response (Sakaguchi et al. 2020; Lachnit et al. 2019). This area of research is an inexhaustible discipline and until today, not much has been done especially when it comes to the bad experiences with food. Much often, many people are still struggling with the side effects of popular restrictive diets on gut health. The strict vegans would attest to this and those feeding on raw food or "clean eating" diets, diets free of gluten. Also with side effects are those on FODMAP (fermentable oligosaccharides, disaccharides, monosaccharide, and polyols), irritable bowel syndrome (IBS) treatment alternative diets (Lebwohl et al. 2017).

\section{Antibiotics and drugs}

The effects of antibiotics can be attributed to the mode of mechanism, the class of antibiotic, the degree of resistance of the antibiotic used and the dosage used during the treatment. In addition, the route of administration, 
the pharmacokinetic and pharmacodynamics properties and the spectrum (broad or narrow) all relatively alters gut microbiota composition (Rogers and Aronoff 2016). Non-steroidal anti-inflammatory drugs are commonly used daily however, these are causative agent for stomach ulcers. Among the consequences, metabolic disorders are extensively studied (Freedberg et al. 2015). Microbes themselves are studied to regulate the drug mechanisms. To have a profound insight as to gut dysbiosis, in addition to the type of drugs used, the existing microbiota, immune system and the intestinal mucosa are the prerequisites. While it is understood that only the bacterial communities are explored in the quest to establishing the role of gut in health, other gut microbial species are somehow contributing to the dysbiosis status of the gut microbiota. Until today, long term natural fluctuations such as diseases outbreaks and mutations of the strain might as well rendering alteration to the gut even before antibiotic treatments. Proton pump inhibitors (PPIs), antidepressants, metformin, laxatives and oral steroids are all studied to confer profound dysbiotic effects on the gut.

\section{Prebiotics}

Among the well characterized bioactive compounds are phytochemicals and Prebiotics, polyunsaturated fatty acids (PUFAs). Prebiotics have proven to be source of fermentation products such as SCFAs that confer diverse biological benefits to the gut (Hill et al. 2014). While PUFA effects advantage to the host immunity and metabolism, phytochemicals are effective bioactive for anti-inflammatory effects, antioxidants, immune modulatory, anti-carcinogenic and anti-estrogenic effects. In addition to these effects, phytochemicals are studied to exert Prebiotics-like effects on gut, thereby inhibiting pathogenic bacteria. In doing so, they are stimulating the growth of the benign bacteria (Laparra and Sanz 2010).

\section{Oxidative stress}

A good number of studies have shown a correlation between increased oxidative stress and reduced gut microbial diversity. The modern dietary habit or the so called western-style diet is rich in fat and refined sugars. These in large quantities, cause an increase of the inflammatory status with reactive oxygen species (ROS) production. Subsequent ROS stimulate the inflammatory cascade (Bellavia et al. 2013). The stress induced by ROS production defined as oxidative stress. Oxidative stress consist of biological system for the process of detoxification and secondary damage repair (Liu et al. 2018). The new study though not supported with enough literature is the potential role of heat shock proteins (HSPs) in the pathogenesis of IBD. HSPs are indentified to play a role in folding, translocation and degradation of intracellular proteins under normal and stressful conditions. They can stimulate an immune response, both innate and adaptive and hence primary targets of the autoimmune response. They are conserved molecules with similar sequences in bacterial and human orthologs (molecular mimicry) (Zhang et al. 2013).

\section{The scoioeconomic status}

The variation in diversity and composition of gut microbes is largely determined by the economic status of the country or region the baby is born and a child is raised. This is due to the available food choices left as the options for mothers to feed their babies. It is a fundamental scientific principle that malnourished individuals are prone to unsteady health conditions and this implies to undernourished infants. Infants that are undernourished lead to dysbiosis condition and abundance of enteropathogens such as Enterobacteriacea being prominent in their gut (Reijnders et al. 2016). A comparative analysis done on two separate studies, that involves infants from rural Africa and European children showed pattern that are directly correlating with the type of diet they consume. Diet dominated by starch, plant polysaccharides and fibre enable the abundance in Bacteroides phyla at 57\% and Actinobacteria at 10\% (Lee et al. 2017). For the European children, due to their diet rich in sugar, animal protein and starch, the abundance of the bacterial population showed a reduce diversity (Alexander et al. 2017). Furthermore, Pretovella, which is a major SCFA were found exclusive to the rural African children microbiota and the same trend is persisting even in healthy human adult consuming high amounts of carbohydrates and some forms of simple sugars (O'Keefe et al. 2015). SCFAs are found to be very significant to the health of gut microbiome and this is manifested in its role in antiinflammatory mechanisms (Spanogiannopoulos et al. 2016). Furthermore, SCFAs (acetate, butyrate and propionate) are studied to be signaling molecules that help in the maintenance of the integrity of colonic epithelium, lipid metabolism, appetite regulation and glucose homeostasis (Morrison et al. 2016).

However, a decreased condition is found among individual feeding on low MACs, the part of dietary fibre that bacteria in large intestine can feed on (Spanogiannopoulos et al. 2016). Unfortunately, nowadays the abundance of MACs is observed in a decreasing trend in the western diet. The establishment of MACs as a major factor for restoring the gut diversity. Mice supplied with a diet of low MAC results to a massive reduction in their gut microbial diversity (Deehan et al. 


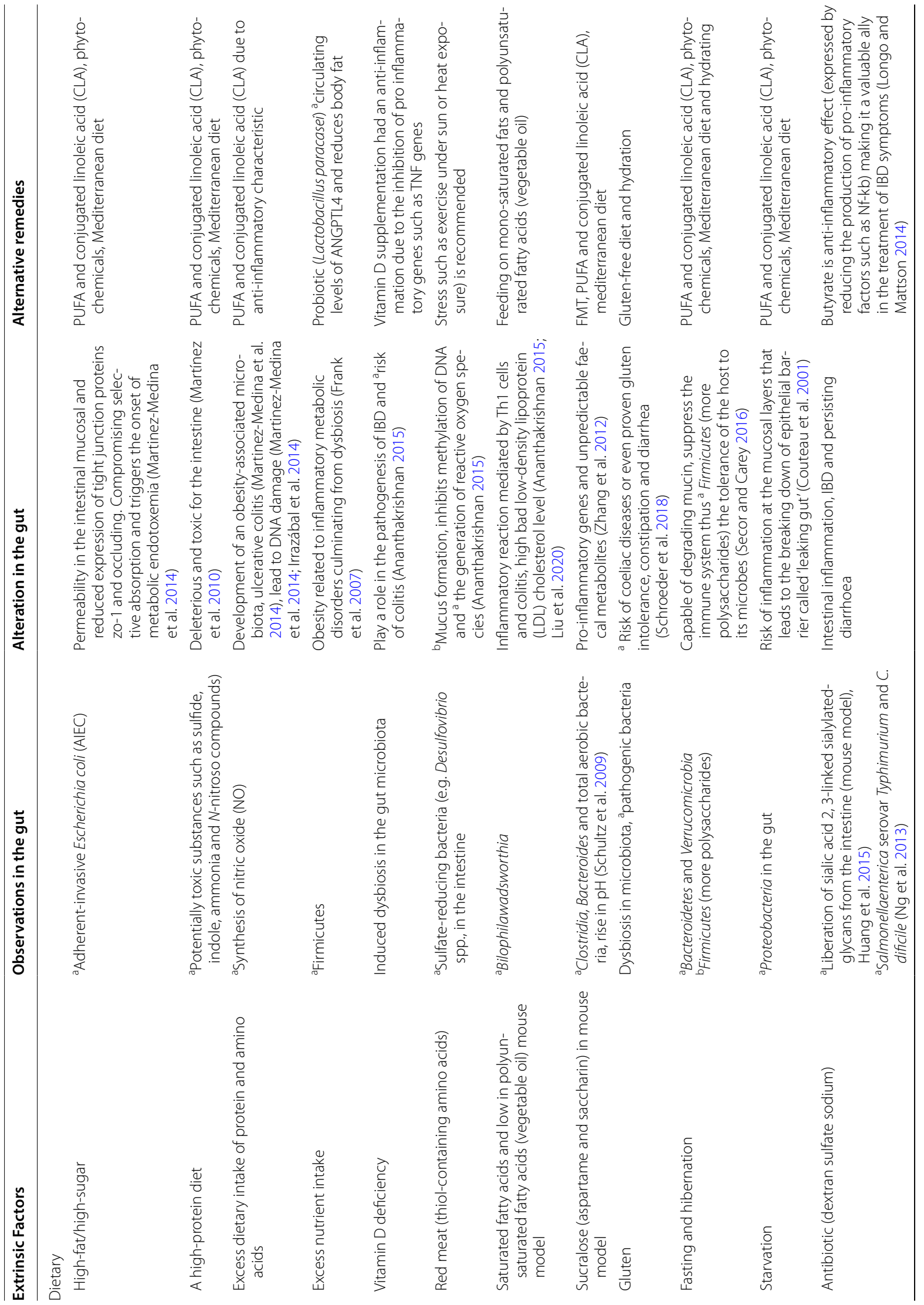




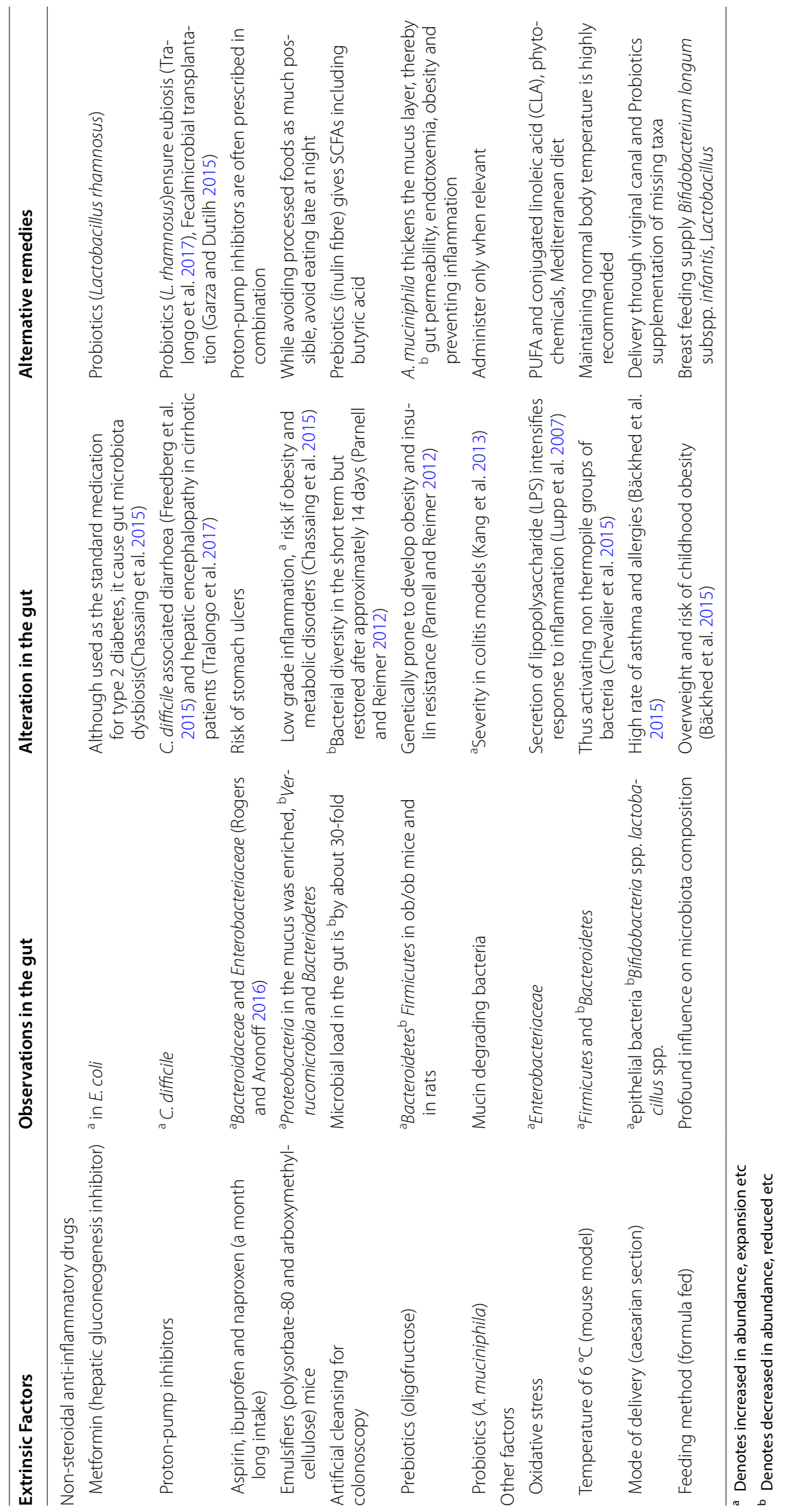


2017). There is hope for children affected with under nutrition since the study using gnotobiotic mice ascertained that some microbial species have the power to restore growth impairments transmitted by microbiota isolated from malnourished children (Martínez et al. 2010). Varying causative factors to dysbiosis in the gut microbiota with consequences of which some have alternative therapeutic approaches (Table 1).

When we lose the diversity of our intestinal microbiota, we are prone to other factors that can be internal or external. Dwelling on these factors, at first, the restoration of these diversities needs to be checked. The administration of MACs and in combination of supplementing the missing taxa is studied to be very efficient (Hooper et al. 2003). In line with this intervention, a study that dealt with malnourished children shows correlating results; gnotobiotic mice revealed that, there are specific microbial species found in malnourished individuals that can cause growth impairments. The administration of some missing taxa are seen to have the ability to restore these impairments. If this study holds for similar results, then there is a big hope that microbes can be used to restore growth impairments from malnourished children and hence another new therapeutic intervention in countering the negative effects of under nutrition (Odenyo et al. 2001). Host intrinsic factors such as genetics can influence the microbial population. However it is not well pronounced when compared with the effects of diet and antibiotics on the microbiota. This was in agreement with results emerging from studies on individuals with contrasting geography and locations, twin studies, and people settling in rural and industrial settlements (Ayeni et al. 2018; Vangay et al. 2018).

Dietary interventions to mitigate and establish positive response of our gut microbes would definitely pave a great way as to determining the effects of microbes and our metabolic response. For example, fibre as is a key nutrient for a healthy microbial composition is hoped to remedy series of autoimmune disorders while the fat and sugar are yet to proof beyond any medicinal evidence. From the time of the edition of this review and even beyond, clinical trial based studies are underway and are not far reaching scientific grounds to prevent the human population against autoimmune and inflammatory diseases. The intervention of the Probiotics and Prebiotics and the FMT are also a competing factor to bring in a desirable change in the gut to ascertain a healthy and normal composition. FMT proves $C$. difficile infection cured more than $90 \%$ of cases (Garza and Dutilh 2015).

\section{Supplementary information}

Supplementary information accompanies this paper at https://doi. org/10.1186/s13568-020-01066-8.

Additional file 1: Figure 1. Factors causing alteration to gut microbiota. Diet rich in protein, amimal fats and high carbohydrate, sucralose and diet containing gluten all contributed to dysbiosis. Exercise and intermittent fasting are studied to both starve the bad microbes and clean the gut. Method of delivery for the newborn baby and the feeding methods determine the childhood immunity and this period is crucial for the development of human life. The $\mathrm{pH}$ level or water quality are as well among the factors associated with dysbiosis. In addition, drugs including antibiotics, non-steroids anti-inflammatory drugs, Prebiotics and Probiotics adversely affected the gut microbiota composition. Other factors are vitamin D deficiency, oxidative stress, temperature and fecal microbial transfer.

\section{Abbreviations}

Gl: Gastrointestinal tract; IBD: Inflammatory bowel diseases; MACs: Microbiotaaccessible carbohydrates; SCFAs: Short chain fatty acid; LPS: Lipopolysaccharide; UC: Ulcerative colitis; CD: Crohn's disease; WSD: Western-style diet; FODMAP: Fermentable oligosaccharides, disaccharides, monosaccharide, and polyols; IBS: Irritable bowel syndrome; PPIs: Proton pump inhibitors; PUFAs: Polyunsaturated fatty acids; ROS: Reactive oxygen species; HSPs: Heat shock proteins; CLA: Conjugated linoleic acid; LDL: Low-density lipoprotein.

\section{Acknowledgements \\ Not applicable.}

\section{Authors' contributions}

OB writes the paper, YT, KAA, GÖ and XQ proofread the paper. All authors read and approved the final manuscript.

\section{Funding}

The publication fee will be reimbursed by Central South University

\section{Availability of data and materials}

Not applicable.

Ethics approval and consent to participate

Not applicable.

\section{Consent for publication}

Not applicable.

\section{Competing interests}

The authors declare that they have no competing interests.

\begin{abstract}
Author details
${ }^{1}$ Respiratory Department, Xiangya Hospital, Central South University, Changsha 410008, Hunan, People's Republic of China. ${ }^{2}$ Department of Medical Microbiology, Central South University, Changsha 410078, Hunan, China. ${ }^{3}$ China-Africa Research Center of Infectious Diseases, School of Basic Medical Sciences, Central South University, Changsha 410078, Hunan, China. ${ }^{4}$ Section of Basic and Industrial Microbiology, Department of Biology, Faculty of Science, Ege University, Izmir, Turkey.
\end{abstract}

Received: 25 April 2020 Accepted: 18 July 2020 Published online: 25 July 2020

\footnotetext{
References

Alexander JL, Wilson ID, Teare J, Marchesi JR, Nicholson JK, Kinross JM (2017) Gut microbiota modulation of chemotherapy efficacy and toxicity. Nat Rev Gastroenterol Hepatol. 14:356-365

Ananthakrishnan AN (2015) Epidemiology and risk factors for IBD. Nat Rev Gastroenterol Hepatol. 12:205-217
} 
Arumugam M, Raes J, Pelletier E, Le Paslier D, Yamada T, Mende DR (2011) Enterotypes of the human gut microbiome. Nature 473(7346):174-180

Ayeni FA, Biagi E, Rampelli S, Fiori J, Soverini M, Audu HJ, Cristino S, Caporali L, Schnorr SL, Carelli V, Brigidi P, Candela M, Turroni S (2018) Infant and adult gut microbiome and metabolome in rural bassa and urban settlers from GUT MICROBES Nigeria. Cell Rep. 23:3056-3067

Bäckhed F, Ding H, Wang T, Hooper LV, Koh GY, Nagy A, Semenkovich CF, Gordon JI (2004) The gut microbiota as an environmental factor that regulates fat storage. Proc Natl Acad Sci USA 101:15718-15723

Bäckhed F, Roswall J, Peng Y, Feng Q, Jia H, Kovatcheva-Datchary P, Li Y, Xia Y, Xie H, Zhong H, Khan MT, Zhang J, Li J, Xiao L, Al-Aama J, Zhang D, Lee YS, Kotowska D, Colding C, Tremaroli V, Yin Y, Bergman S, Xu X, Madsen L, Kristiansen K, Dahlgren J, Wang J (2015) Dynamics and stabilization of the human gut microbiome during the first year of life. Cell Host Microbe 17:852

Bellavia M, Tomasello G, Romeo M, Damiani P, Lo Monte Al, Lozio L, Campanella C, Marino Gammazza A, Rappa F, Zummo G, Cocchi M, Conway de Macario E, Macario AJ, Cappello F (2013) Gut microbiota imbalance and chaperoning system malfunction are central to ulcerative colitis pathogenesis and can be counteracted with specifically designed probiotics: a working hypothesis. Med Microbiollmmunol. 202:393-406

Bonder MJ, Tigchelaar EF, Cai X, Trynka G, Cenit MC, Hrdlickova B, Zhong H, Vatanen T, Gevers D, Wijmenga C, Wang Y, Zhernakova A (2016) The influence of a short-term gluten-free diet on the human gut microbiome. Genome Med. 8:45

Chassaing B, Koren O, Goodrich JK, Poole AC, Srinivasan S, Ley RE, Gewirtz AT (2015) Dietary emulsifiers impact the mouse gut microbiota promoting colitis and metabolic syndrome. Nature 519:92-96

Chevalier C, Stojanović O, Colin DJ, Suarez-Zamorano N, Tarallo V, VeyratDurebex C, Rigo D, Fabbiano S, Stevanović A, Hagemann S, Montet X, Seimbille Y, Zamboni N, Hapfelmeier S, Trajkovski M (2015) Gut microbiota orchestrates energy homeostasis during cold. Cell 163:1360-1374

Couteau D, McCartney AL, Gibson GR, Williamson G, Faulds CB (2001) Isolation and characterization of human colonic bacteria able to hydrolysechlorogenic acid. J Appl Microbiol 90:873-881

David LA, Maurice CF, Carmody RN, Gootenberg DB, Button JE, Wolfe BE, Ling AV, Devlin AS, Varma Y, Fischbach MA, Biddinger SB, Dutton RJ, Turnbaugh PJ (2013) Diet rapidly and reproducibly alters the human gut microbiome. Nature 505:559-563

Deehan EC, Duar RM, Armet AM, Perez-Muñoz ME, Jin M, Walter J (2017) Modulation of the gastrointestinal microbiome with nondigestible fermentable carbohydrates to Improve human health. Microbiol Spectr. 5:5

Frank DN, St Amand AL, Feldman RA, Boedeker EC, Harpaz N, Pace NR (2007) Molecular-phylogenetic characterization of microbial community imbalances in human inflammatory bowel diseases. Proc Natl Acad Sci USA 104:13780-13785

Freedberg DE, Toussaint NC, Chen SP, Ratner AJ, Whittier S, Wang TC, Wang $\mathrm{HH}$, Abrams JA (2015) Proton pump inhibitors alter specific taxa in the human gastrointestinal microbiome: a crossover trial. Gastroenterology 149:883-885.e9

Garza DR, Dutilh BE (2015) From cultured to uncultured genome sequences: metagenomics and modeling microbial ecosystems. Cell Mol Life Sci 72:4287-4308

Gibson PR (2017) The evidence base for efficacy of the low FODMAP diet in irritable bowel syndrome: is it ready for prime time as a first-line therapy? J Gastroenterol Hepatol 32:32-35

Guarner F, Malagelada JR (2003) Gut flora in health and disease. Lancet 361(9356):512-519

Hill C, Guarner F, Reid G, Gibson GR, Merenstein DJ, Pot B, Morelli L, Canani RB, Flint HJ, Salminen S, Calder PC, Sanders ME (2014) Expert consensus document. The International Scientific Association for Probiotics and Prebiotics consensus statement on the scope and appropriate use of the term probiotic. Nat Rev Gastroenterol Hepatol. 11:506-514

Hooper LV, StappenbeckTS, Hong CV, Gordon JI (2003) Angiogenins: a new class of microbicidal proteins involved in innate immunity. Nat Immunol 4:269-273

Huang YL, Chassard C, Hausmann M, von Itzstein M, Hennet T (2015) Sialic acid catabolism drives intestinal inflammation and microbial dysbiosis in mice. Nat Commun. 6:8141

Irrazábal T, Belcheva A, Girardin SE, Martin A, Philpott DJ (2014) The multifaceted role of the intestinal microbiota in colon cancer. Mol Cell 54:309-320
Kang CS, Ban M, Choi EJ, Moon HG, Jeon JS, Kim DK, Park SK, Jeon SG, Roh TY, Myung SJ, Gho YS, Kim JG, Kim YK (2013) Extracellular vesicles derived from gut microbiota, especially Akkermansia muciniphila, protect the progression of dextran sulfate sodium-induced colitis. PLOS ONE 8:e76520

Kasai C, Sugimoto K, Moritani I, Tanaka J, Oya Y, Inoue H, Tameda M, Shiraki K, Ito M, Takei Y, Takase K (2015) Comparison of the gut microbiota composition between obese and non-obese individuals in a Japanese population, as analyzed by terminal restriction fragment length polymorphism and next-generation sequencing. BMC Gastroenterol. 15:100

Kim HY, Lee HJ, Chang YJ, Pichavant M, Shore SA, Fitzgerald KA, Iwakura Y, Israel E, Bolger K, Faul J, DeKruyff RH, Umetsu DT (2014) Interleukin-17-producing innate lymphoid cells and the NLRP3 inflammasome facilitate obesity-associated airway hyperreactivity. Nat Med. 20:54-61

Lachnit T, Bosch TCG, Deines P (2019) Exposure of the host-associated microbiome to nutrient-rich conditions may lead to dysbiosis and disease development - an evolutionary perspective. mBio 10:e00355-19

Laparra MJ, Sanz Y (2010) Interactions of gut microbiota with functional food components and nutraceuticals. Pharm Res 61:219-225

Lebwohl B, Cao Y, Zong G, Hu FB, Green PHR, Neugut Al, Rimm EB, Sampson L, Dougherty LW, Giovannucci E, Willett WC, Sun Q, Chan AT (2017) Long term gluten consumption in adults without celiac disease and risk of coronary heart disease: prospective cohort study. BMJ 357:j1892

Lee YM, Kim KS, Jacobs DR Jr, Lee DH (2017) Persistent organic pollutants in adipose tissue should be considered in obesity research. Obes Rev 18:129-139

Ley RE, Lozupone CA, Hamady M, Knight R, Gordon Jl (2008) Worlds within worlds: evolution of the vertebrate gut microbiota. Nat Rev Microbiol 6:776-788

Liu X, Blouin JM, Santacruz A, Lan A, Andriamihaja M, Wilkanowicz S, Benetti PH, Tomé D, Sanz Y, Blachier F, Davila AM (2014) High-protein diet modifies colonic microbiota and luminal environment but not colonocyte metabolism in the rat model: the increased luminal bulk connection. Am J Physiol Gastrointest Liver Physiol 307:G459-G470

Liu CX, Tan YR, Xiang Y, Liu C, Liu XA, Qin XQ (2018) Hydrogen sulfide protects against chemical hypoxia-Induced injury via attenuation of ROS-mediated $\mathrm{Ca} 2+$ overload and mitochondrial dysfunction in human bronchial epithelial cells. Biomed Res Int 2018:2070971

Liu D, Tan Y, Bajinka O, Wang L, Tang Z (2020) Th17/IL-17 axis regulated by airway microbes get involved in the development of asthma. Curr Allergy Asthma Rep. 20:11

Longo VD, Mattson MP (2014) Fasting: molecular mechanisms and clinical applications. Cell Metab 19:181-192

Lupp C, Robertson ML, Wickham ME, Sekirov I, Champion OL, Gaynor EC, Finlay BB (2007) Host-mediated inflammation disrupts the intestinal microbiota and promotes the overgrowth of Enterobacteriaceae. Cell Host Microbe 2:119-129

Ma Q, Xing C, Long W, Wang HY, Liu Q, Wang RF (2019) Impact of microbiota on central nervous system and neurological diseases: the gut-brain axis. J Neuroinflamm 16:53

Magee EA, Richardson CJ, Hughes R, Cummings JH (2000) Contribution of dietary protein to sulfide production in the large intestine: an in vitro and a controlled feeding study in humans. Am J Clin Nutr 72:1488-1494

Martínez I, Kim J, Duffy PR, Schlegel VL, Walter J (2010) Resistant starches types 2 and 4 have differential effects on the composition of the fecal microbiota in human subjects. PLoS ONE 5:e15046

Martinez-Medina M, Denizot J, Dreux N, Robin F, Billard E, Bonnet R, DarfeuilleMichaud A, Barnich N (2014) Western diet induces dysbiosis with increased E coli in CEABAC10 mice, alters host barrier function favouring AIEC colonisation. Gut 63:116-124

Morrison DJ, Preston T, Morrison DJ, Preston T (2016) Formation of short chain fatty acids by the gut microbiota and their impact on human metabolism. Gut Microbes. 7:189-200

Nettleton JE, Reimer RA, Sheare J (2016) Reshaping the gut microbiota: impact of low calorie sweeteners and the link to insulin resistance? Physiol Behav 164:488-493

Ng KM, Ferreyra JA, Higginbottom SK, Lynch JB, Kashyap PC, Gopinath S, Naidu N, Choudhury B, Weimer BC, Monack DM, Sonnenburg JL (2013) Microbiota-liberated host sugars facilitate post-antibiotic expansion of enteric pathogens. Nature 502:96-99 
Odenyo AA, Bishop R, Asefa G, Jamnadass R, Odongo D, Osuji P (2001) Characterization of tannin-tolerant bacterial isolates from East African ruminants. Anaerobe 7:5-15

O'Keefe SJ, Li JV, Lahti L, Ou J, Carbonero F, Mohammed K, Posma JM, Kinross J, Wahl E, Ruder E, Vipperla K, Naidoo V, Mtshali L, Tims S, Puylaert PG, DeLany J, Krasinskas A, Benefiel AC, Kaseb HO, Newton K, Nicholson JK, de Vos WM, Gaskins HR, Zoetendal EG (2015) Fat, fibre and cancer risk in African Americans and rural Africans. Nat Commun. 6:6342

Parnell JA, Reimer RA (2012) Prebiotic fibres dose-dependently increase satiety hormones and alter Bacteroidetes and Firmicutes in lean and obese JCR:LA-Cp rats. Br J Nutr 107:601-613

Peng J, Xiao X, Hu M, Zhang X (2018) Interaction between gut microbiome and cardiovascular disease. Life Sci 214:153-157

Qiu X, Ye Q, Sun M, Wang L, Tan Y, Wu G (2020) Saturated hydrogen improves lipid metabolism disorders and dysbacteriosis induced by a high-fat diet. Exp Biol Med (Maywood). 245:512-521

Reijnders D, Goossens GH, Hermes GD, Neis EP, van der Beek CM, Most J, Holst J, Lenaerts K, Kootte RS, Nieuwdorp M, Groen AK, Olde Damink SW, Boekschoten MV, Smidt H, Zoetendal EG, Dejong CH, Blaak EE (2016) Effects of gut microbiota manipulation by antibiotics on host metabolism in obese humans: a randomized double-blind placebo-controlled trial. Cell Metab 24:63-74

Rogers MA, Aronoff DM (2016) The influence of non-steroidal anti-inflammatory drugs on the gut microbiome. Clin Microbiol Infect 22(178):e1-e9

Saha JR, Butler VP, Neu HC, Lindenbaum J (2017) Digoxin-inactivating bacteria: identification in human gut flora. Science 220:325-327

Sakaguchi S, Nakagawa S, Mitsuhashi S, Ogawa M, Sugiyama K, Tamukai K, Koide R, Katayama Y, Nakano T, Makino S, Imanishi T, Miyazawa T, Mizutani $T$ (2020) Molecular characterization of feline paramyxovirus in Japanese cat populations. Arch Virol 165(2):413-418

Sartor RB, Mazmanian SK (2012) Intestinal microbes in inflammatory bowel diseases. Am J Gastroenterol Suppl. 1:15-21

Schultz PG, Peters EC, Liu J, Wikoff WR, Anfora AT, Siuzdak G, Lesley SA (2009) Metabolomics analysis reveals large effects of gut microflora on mammalian blood metabolites. Proc Natl Acad Sci USA 106:3698-3703

Schroeder BO, Birchenough GMH, StåhIman M, Arike L, Johansson MEV, Hansson GC, Bäckhed F (2018) Bifidobacteria or fiber protects against diet-induced microbiota-mediated colonic mucus deterioration. Cell Host Microbe 23:27-40.e7

Secor SM, Carey HV (2016) Integrative physiology of fasting. Compr Physiol 6:773-825

Silva FMCE, Oliveira EE, Ambrósio MGE (2020) High-fat diet-induced obesity worsens $\mathrm{TH} 2 \mathrm{immune}$ response and immunopathologic characteristics in murine model of eosinophilicoesophagitis. Clin Exp Allergy 50:244-255
Spanogiannopoulos P, Bess EN, Carmody RN, Turnbaugh PJ (2016) The microbial pharmacists within us: a metagenomic view of xenobiotic metabolism. Nat Rev Microbiol 14:273-287

Thaiss CA, Zmora N, Levy M, Elinav E (2016) The microbiome and innate immunity. Nature 535:65-74

Tralongo P, Tomasello G, Sinagra E, Chu C, Huang Y, Lin H, Hou M, Lee F, Su T, Lu C (2017) Proton pump inhibitors increase risk for hepatic encephalopathy in patients with cirrhosis in a population study. Gastroenterology 152:134-141

Travisano M, Velicer GJ (2004) Strategies of microbial cheater control. Trends Microbiol 12:72-78

Vangay P, Johnson AJ, Ward TL, Al-Ghalith GA, Shields-Cutler RR, Hillmann BM, Lucas SK, Beura LK, Thompson EA, Till LM, Batres R, Paw B, Pergament SL, Saenyakul P, Xiong M, Kim AD, Kim G, Masopust D, Martens EC, Angkurawaranon C, McGready R, Kashyap PC, Culhane-Pera KA, Knights D (2018) US immigration Westernizes the human gut microbiome. Cell 175(962-972):e10

Wu GD, Compher C, Chen EZ, Smith SA, Shah RD, Bittinger K, Chehoud C, Albenberg LG, Nessel L, Gilroy E, Star J, Weljie AM, Flint HJ, Metz DC, Bennett MJ, Li H, Bushman FD, Lewis JD (2016) Comparative metabolomics in vegans and omnivores revealconstraints on diet-dependentgut microbiota metabolite production. Gut 65:63-72

Yee KC, Estaki M, Gibson DL (2013) Clinical consequences of diet-Induced dysbiosis. Ann Nutr Metab 63:28-40

Zhang C, Zhang M, Pang X, Zhao Y, Wang L, Zhao L (2012) Structural resilience of the gut microbiota in adult mice under high-fat dietary perturbations. ISME J 6:1848-1857

Zhang C, Li S, Yang L, Li W, Wang S, Zhao G, Zhang M, Pang X, Yan Z, Liu Y, Zhao $L$ (2013) Structural modulation of gut microbiota in life-long calorierestricted mice. Nat Commun. 4:2163

Zoetendal EG, Raes J, van den Bogert B, Arumugam M, Booijink CCGM, Troost FJ, Bork P, Wels M, de Vos WM, Kleerebezem M (2012) The human small intestinal microbiota is driven by rapid uptake and conversion of simple carbohydrates. ISME J 6:1415-1426

\section{Publisher's Note}

Springer Nature remains neutral with regard to jurisdictional claims in published maps and institutional affiliations.

\section{Submit your manuscript to a SpringerOpen ${ }^{\odot}$ journal and benefit from:}

- Convenient online submission

- Rigorous peer review

- Open access: articles freely available online

- High visibility within the field

- Retaining the copyright to your article

Submit your next manuscript at $\boldsymbol{\nabla}$ springeropen.com 